\title{
Evaluation of efficiency and its determinants in Croatian hotel industry
}

\author{
Maja Pervan, Petra Babic \\ University of Split, Faculty of Economics, Business and Tourism, Split, Croatia \\ Received: July 29, 2021. Revised: November 16, 2021. Accepted: December 10, 2021. Published: December 29, 2021.
}

\begin{abstract}
The main objective of this research was to evaluate the efficiency of Croatian hotels and provide insights into the sources of their efficiency. In order to obtain set goals, a twostage analysis was performed on a sample of 69 large and medium-size hotels that were operating in Croatia in 2019. In the first stage of analysis, the efficiency scores of hotels were obtained by using Data envelopment analysis (DEA), whereas in the second stage of analysis, achieved efficiency coefficients were served as dependent variable in a truncated regression model in which hotel's ownership, age, location, size and star rating were applied as independent variables. As this is the first time that efficiency of Croatian hotel industry is investigated with the application of truncated regression analysis, this research contributes to the existing literature by shading new lights on the sources of hotels' efficiency from the perspective of a country heavily relaying on seasonal seaside tourism. Results of the research showed that all analysed variables (except age) play significant and important role in determining the achieved level of efficiency.
\end{abstract}

Keywords - Croatia, efficiency and determinants of efficiency, hotel industry

\section{INTRODUCTION}

Tourism is becoming increasingly important in the world economy today. It accounts for a significant share of GDP and employs a large share of the workforce in many countries around the globe [1]. The last decade has been marked by the constant growth of tourist arrivals, which in 2019 reached a peak of 1.5 billion globally [2]. A turning point was in 2020 in which travel bans and restrictions were introduced to curb the spread of the Covid-19. The number of international tourist arrivals in the world in the first eight months of 2020 fell by 70 percent compared to the same period in 2019, resulting in the decrees of 700 million of foreign tourist arrivals. Losses of export revenues from international tourism amounted to 730 billion USD. The severity of the situation is reflected in the fact that this loss is eight times greater than the one in 2009, caused by the global economic and financial crisis [2]. Hotel industry is the foundation of the tourism sector in terms of income levels, investments, and the impact on the employment. It also plays a key role in making the tourist season last longer [3]. Due to the growing demand for travel and higher disposable incomes, the hotel industry has a great growth potential. The constant increase in competition has led hotels to boost their performance in order to stay competitive.
The quality of the hotel, the variety of services and security, could all be crucial in the current period of the Corona Crisis when hotels need to make additional efforts and "fight" for each individual guest.

Tourism in Croatia is following the world trends. The importance of tourism for the Croatian economy is reflected in the fact that foreign exchange income from tourism accounted for 19.4 percent of GDP and 37.3 percent of total Croatian exports in 2019 [4]. Like world tourism, Croatian tourism has suffered severe consequences of the Covid-19 pandemic. For example, in the first nine months of 2020, a 6.7 million tourist arrivals and 39.7 million overnight stays were recorded in Croatia. This presents only 37.6 percent of arrivals and 45.9 percent of the number of overnight stays during the same period in 2019 [4].

Given the type of accommodation, Croatian hotels record the highest occupancy rates throughout the year [5]. Hotel traffic has grown continuously over the years and in 2019 reached the level of 7.9 million arrivals and almost 26 million overnight stays. Although they make up only 13.3 percent of the total number of accommodation capacities, they realised 24 percent of the total number of overnight stays of foreign tourists in 2019. According to the data of Business Croatia, 1,345 active business entities were recorded in NACE class 55.10 "Hotels and similar accommodation" in 2019 and they generated total revenues of HRK 17.5 billion [4].

Considering the consequences of the Corona crisis, all types of accommodation have recorded a decrease in tourist arrivals and overnight stays compared to the same period last year. However, the largest decline was recorded in the hotel accommodation. In July 2020, they have recorded 60.7 percent less overnight stays compared to the same month in 2019 [4]. Due to this situation, hotels need to achieve the highest possible level of their efficiency and ensure smooth functionality. Therefore, the aim of this paper is to examine the level of efficiency of Croatian hotels in 2019 as well as to identify and analyse the influence of independent factors that determine hotels' efficiency. In order to create a homogeneous sample, only large and medium-sized hotels for which all necessary data were available have been included in the analysis, making in total 69 hotels that operated independently or as a part of a hotel group in 2019. Such sample selection is in line with previous research [6], [7] in which variable ownership (together with the other variables in the later stage of analysis) was used as a determinant of hotels' efficiency. 
To the best of authors' knowledge, only one paper were dealing with the efficiency of Croatian hotels and in that paper a relation of efficiency and hotels' age and size were examined through two separate tests. However, given that the model which simultaneously (not individually and/or separately) encompasses and analyses potential influential factors can provide more accurate and comprehensive insight into the determinants of efficiency, this paper contributes to the existing literature by shading new lights on the sources of hotels' efficiency from the perspective of a country heavily relaying on seasonal seaside tourism. Moreover, this is the first time that the determinants of the efficiency of Croatian hotel industry were examined with the application of truncated regression analysis in which, aside from age and size, additional determinants i.e. ownership, location and star rating of the hotel were applied.

The study unfolds as follows. After the introductory section explaining the motives for conducting this research, the next section provides literature review related to the hotel efficiency. Third section gives insights into methodology as well as inputs and outputs used in DEA analysis and truncated regression. Fourth section provides efficiency scores and results of the truncated regression analysis, whereas the last section offers a conclusion.

\section{LITERATURE REVIEW}

Reference [6] conducted a first application of DEA methodology in hotel industry and since then, the literature of efficiency in the hospitality industry has developed rapidly. An overview of some of the research from Asia ([7], [8], [9], [10], [11], [12]), Europe ([13], [14], [15], [16]), South America [17], Australia [18] and Africa [19] is given below.

Authors [7] selected 58 hotels in seven different regions in Oman to measure efficiency using the DEA methodology. The inputs consisted of number of beds, number of rooms, number of employees and salary of employees. As outputs, the authors used annual revenue, number of guests, number of nights and occupancy rate. The average efficiency score obtained by input oriented CCR and BCC model was 0.70 and 0.83 respectively. The impact of contextual factors was also examined, showing that type of ownership (independent or chain dependent), nature and activities play no important role in hotels' efficiency, whereas hotel size, star rating and cultural attractions have the most significant effect on efficiency. On the other hand, in the research [8], it was discovered that the hotel size has no significant impact on efficiency. Reference [9] aimed to create a DEA model that should solve the problem of zero or small values of inputs or outputs when calculating the efficiency of 21 hotels in Taiwan. Inputs used in the research were number of employees, operating cost, number of guest rooms and the total area of the restaurant, whereas the output variables were revenues and rooms occupancy. The authors compared the standard CCR model with the new, proposed model and revealed that since proposed model avoided the occurrence of zero values, the efficiency values were lower than in the standard CCR model. In addition, the advantage of the new model was the ability of providing a complete ranking for all hotels. Reference [10] examined the efficiency of 28 4-star and 5-star resort hotels in coastal Turkish regions in 2005 with output oriented CRS and VRS models. The authors used room capacity, personnel cost, energy cost, F\&B cost and other cost as inputs, whereas as outputs applied modified revenue per available room and other revenue per room sold. Average value accomplished by CRS and VRS models were 0.71 and 0.79 respectively. Results revealed that 4-star hotels were quite efficient, whereas management style (independent or chain hotel) has no significant impact on efficiency. Reference [11] analysed the efficiency of 39 hotels in Korea using output oriented CRS model. As inputs, the authors applied cost of land property, building capacity, other assets and operating costs, whereas as outputs considered revenue (room, food/beverage and other revenues) and income (operating and non-operating). Four main conclusions were drawn: (1) hotel size is not a good indicator of its efficiency in generating income, (2) the location in heavily populated areas does not necessarily reflect the hotel's financial efficiency, (3) there is no evidence that franchised chain hotels are more efficient than independent ones and (4) instead of relying only on room revenue, hotels should diversify their revenue sources in order to enhance their financial efficiency. Research of [12] used DEA methodology to examine hotel efficiency in 31 Chinese regions in 2006 by applying output oriented CCR and BCC models. In form of inputs, the authors employed a total number of full-time employees, total number of rooms and total fixed assets, whereas as outputs used total revenue and average occupancy rate. A cluster analysis that was performed revealed that the average efficiency value in high-efficiency regions was 0.95 , in medium-efficiency regions 0.705 , and in low-efficiency regions 0.539 . Eastern regions make up $50 \%$ of low-efficiency cluster, which calls into question the common opinion that eastern China generally outperforms its counterparts in terms of production efficiency. Furthermore, it was found that major economic centers were associated with relatively low levels of overall efficiency.

Croatian authors [13] used output oriented CCR model to examine efficiency of 105 hotels in Croatia in 2013. They concluded that a low average efficiency rate of 73 percent most likely stems from a low average occupancy rate. Although differences in efficiency among hotels of a different quality and size were examined, the result showed only significant relationship between efficiency and hotel size. Efficiency scores of 13 companies with 20 5-star hotels and 15 companies with 364 -star hotels were examined in the Algarve from 2005 to 2007 [14]. Two models were implemented; the first one with quantitative and the second one with monetary units. Inputs used in the first model referred to rooms, employees, F\&B capacity and other costs, whereas the second model employed capital costs, staff costs and other costs. Both models applied total revenue as output variable. Values of input oriented CRS and VRS models amounted 0.519 and 0.729 , whereas in the output oriented models were 1.923 and 1.534 respectively. By using the DEA methodology, [15] conducted a research on a sample of 50 luxury and A-class hotels operating either as independent or under a brand in 
Crete. The branded hotels were classified into three categories: hotels operating under a local, national or international brand. The input variables used in the study were the total operational cost of a hotel, number of beds and number of employees, whereas the output variables were the total number of nights spent in a hotel and total revenues. The average efficiency values of the input oriented CCR and BCC models were 80.1 and 87.35 respectively. Two conclusions were drawn. First, internationally branded hotels were the least efficient, whereas hotels operating under a national and local brand were relatively most efficient as they are flexible to changes in local market conditions. Second, the main reason of hotels inefficiency is due to their input/output configuration as well as due to the size of their operations. With the application of DEA methodology, [16] analysed the efficiency of 15 Portuguese hotels for the period 1998-2002. Number of employees and physical capital were used as inputs, whereas sales, value added and earnings were applied as outputs. Application of CRS and VRS output oriented models resulted with average efficiencies of 0.730 and 0.819 respectively. The authors discovered that scale was the main factor in explaining economic efficiency and that there were no special regional or property characteristics that would influence the results.

Research in Ecuador [17] applied DEA methodology on a sample of 147 businesses between 2013 and 2017. The inputs used in the study were total personnel, non-current assets and consumption, whereas revenue was used as only output. The average efficiency by province and years was 0.658 . The conclusion obtained from input oriented CRS model was that third category hotels were on average the most efficient in most provinces. In addition, the influence of the location was examined and it was found that hotels that operated in tourist areas used their inputs in a better way. Reference [18] performed DEA to assess the technical efficiency of Australian hotels for the period 2004-2007. The average efficiency score in output oriented VRS model was 80.84 percent in 2007. Inputs were presented by six indicators: room payroll, other payroll, food cost, beverages cost, room expenses and number of available rooms. On the other hand, room revenues and food \& beverages revenues were used as output variables. The results indicated that number of years in business, location, star rating and physical size were all positive and statistically significant in influencing the hotel efficiency. By applying DEA methodology, [19] evaluated the technical efficiency of 12 hotels in Luanda over the years 2000-2006. DEA methodology with output oriented CRS model was applied. Inputs were measured with two indicators: total costs and investment expenditure, whereas output variable was revenue per room. The results of the analysis revealed that average hotel efficiency was 0.876 and that hotel's membership in a group increased efficiency.

\section{METHODOLOGY AND VARIABLES}

In this research, a two-stage analysis was applied. In order to obtain efficiency coefficient for each hotel included in the sample, in the first stage of investigation a Data envelopment analysis was performed, whereas in the second stage of analysis, achieved efficiency coefficients were used as dependent variable in a truncated regression model.

As a non-parametric technique that is based on liner programming, Data envelopment analysis is usually applied in research that aims to evaluate relative efficiency of business entities (i.e. firms or hotels, afterwards decision-making units DMUs). After the seminal work of Farrel [20], the authors Charnes, Cooper and Rhodes [21] established CCR model based on the presumption of constant returns to scale (CRS), whereas later on Banker, Charnes and Cooper [22] developed $\mathrm{BCC}$ model, founded on the assumption of variable returns to scale (VRS). As CCR model assumes no significant association between efficiency and scales of operation, it estimates overall technical efficiency (OTE) of DMUs. On the other hand, BCC model calculates pure technical efficiency (PTE), which in combination with the scale efficiency (SE) enables decomposition of OTE. According to the model orientation, DEA models can be categorised as input and output oriented. Whereas the first ones are concentrated on input minimization though remaining output constant, the second ones are focused on output maximisation with the given inputs. In both of these models, DEA analysis separates efficient DMUs (whose efficiency scores amounted 100\%) from those inefficient (with efficiency score lower than 100\%). Efficient DMUs create efficient frontier compared to which each DMU's efficiency measure (in relation to that of all other DMUs) is calculated. Based on the above presented, in this research an output oriented CCR model is applied. Model selection is in line with the study of [7], [9] and many others. In order to accomplish the analysis, a Performance Improvement Management Software (PIM-DEA) is applied.

According to microeconomic theory, in every production process a business entity (i.e. DMU) uses inputs such as capital, labour and/or land/materials in order to produce and sell goods or services. If DMU is successful, it will achieve the set goals, usually expressed in terms of profit maximization, revenue maximization or firm growth as stated in neo-classical and managerial theories of the firm. Therefore, in line with stated, four inputs (number of rooms, number of beds, costs of raw materials and supplies, and number of employees) and one output (operating revenue) were used in DEA analysis. The selection of inputs and output was guided by theoretical literature and empirical research, as well as by data availability, while taking into account researchers' recommendation about the number of variables (inputs and outputs) suitable for the analysis. According to [23], minimal number of DMUs should be at least three times the number of inputs and outputs used in the investigation. Since the number of hotels included in the sample (69) considerably exceeded the number of variables applied in this research (5), the latter condition was fulfilled.

As regards truncated regression, it is commonly applied in models in which sample has been truncated below or above specific thresholds of the regressand, meaning that some observations (based on a certain value of the regressand) are systematically removed from the sample. Although some 
researchers apply OLS regression (e.g. [24], [25]) to estimate regression coefficients, it must be noted that the application of OLS would produce biased parameter estimates as the efficiency scores of some hotels may achieve value of $100 \%$ (recall that boundaries of efficiency span between $0 \%$ and $100 \%$ ). Therefore, a truncated regression, in which parameters are estimated via parametric maximum likelihood method, is preferable in this kind of research.

As a regressand or dependent variable, efficiency scores evaluated in the first stage of the analysis were applied, whereas as independent variables we used hotel's ownership, age, location, size and hotel's star rating. Each of the listed variable is calculated in the following manner: hotel's ownership is a dichotomous variable taking a value of 1 in case of independent hotel and zero otherwise; hotel's age denote a number of years that hotel operates in the hospitality industry; hotel's location is a dichotomous variable taking a value of 1 if hotel is located in the county by the sea, zero otherwise; hotel's size is measured as natural logarithm of hotel's total revenue; and hotel's star rating represents the number of stars associated to a particular hotel. Justification for the inclusion of the presented variables can be found in theoretical literature as well as in previously presented empirical research (e.g. [7], [13] and [17]). All necessary data (except for the number of hotel's stars, for which information were collected from the web pages of Croatian Ministry of Tourism) were obtain from "info.BIZ 2.0" - database of Croatian Financial Agency [26]. This part of the empirical analysis was performed with STATA software.

\section{RESULTS AND DISCUSSION}

Before conducting DEA analysis, a correlation among selected inputs and outputs that on the most convenient way present functioning of hotels, must be performed. Results are presented in Table I, from which a strong positive and statistically significant relationship among four inputs (number of rooms, number of beds, costs of raw materials and supplies and number of employees) and one output (operating revenue) can be observed.

The lowest level of coefficient is recorded between operating revenue and number of rooms (0.922). Furthermore, as the coefficients of all variables are positive (meaning that an increase in inputs will cause increase in output), the data fulfil isotonicity [27], hence the analysis can be performed with DEA methodology.

Table I Results of correlation analysis

\begin{tabular}{|c|c|c|c|c|c|}
\hline Variable & $\begin{array}{l}\text { Number } \\
\text { of rooms }\end{array}$ & $\begin{array}{l}\text { Number } \\
\text { of beds }\end{array}$ & $\begin{array}{l}\text { Costs of } \\
\text { raw } \\
\text { materials } \\
\text { and } \\
\text { supplies }\end{array}$ & $\begin{array}{c}\text { Number } \\
\text { of } \\
\text { employees }\end{array}$ & $\begin{array}{c}\text { Operating } \\
\text { revenue }\end{array}$ \\
\hline $\begin{array}{l}\text { number of } \\
\text { rooms }\end{array}$ & 1.000 & & & & \\
\hline number of beds & 0.998 & 1.000 & & & \\
\hline $\begin{array}{l}\text { costs of raw } \\
\text { materials and } \\
\text { supplies }\end{array}$ & 0.925 & 0.930 & 1.000 & & \\
\hline $\begin{array}{l}\text { number of } \\
\text { employees }\end{array}$ & 0.931 & 0.939 & 0.991 & 1.000 & \\
\hline $\begin{array}{l}\text { operating } \\
\text { revenue }\end{array}$ & 0.922 & 0.928 & 0.995 & 0.990 & 1.000 \\
\hline
\end{tabular}

Source: Authors`calculations

Results of the output oriented CCR model, which was applied on 69 hotels that were operating in Croatian hospitality industry in 2019, are presented in Table II. For confidentiality reasons, a specific label (DMU number) is assigned to each hotel. According to the overall technical efficiency (OTE), out of 69 hotels, only three of them $(4.35 \%)$ were efficient as their efficiency score amounted to $100 \%$. The efficient hotels form reference set for all inefficient hotels (66 hotels whose efficiency scores are less than $100 \%$ ) and their operating practice can serve as a pattern that inefficient hotels should follow. Average value OTE in hotel industry is 51.32\% suggesting that on average a hotel can reduce its inputs (resources) or augment its outputs (services) by $48.68 \%$ in order to achieve frontier efficiency i.e. to become efficient. Less than half of analysed hotels (45\%) perform at a level above the average.

When comparing obtained results with those of [13] for Croatia and those of other studies performed at the European level (e.g., [14], [15], [16]), our results show lower level of efficiency than previous research. Possible explanation for such a finding can be due to different sample selection e.g. [13] included in their analysis 105 hotels of all size, whereas we focused our attention only on large and medium-size hotels as we wanted to create as much as possible homogeneous sample for DEA analysis. Likewise, [14] examined efficiency of hotel companies with 4-star and 5-star hotels; [15] focused only on 50 luxury and A-class hotels, whereas [16] analysed efficiency of relatively small number of hotels (15 of them). Additionally, a different combination of used input/output variables could also create a difference between obtained results. Aside from some differences in sample and variable selection, possible reason for relatively low level of achieved efficiency may lie in high cost of raw materials/supplies and high labour costs as well as low occupancy rate and consequently low operating revenue realised by hotels from our sample.

Nevertheless, as efficiency (in general sense) represents the ratio of outputs and inputs, every hotel can improve its efficiency either by reducing used inputs whereas keeping output constant or by augmenting outputs whereas holding inputs unchanged or by simultaneously reducing inputs and 
augmenting outputs. Analysis of inputs and outputs used in this research showed that most hotels from our sample provide a relative oversupply of rooms/beds and are relatively overstaffed, and hence are not able to achieve high levels of operating revenues as their efficient counterparts. Therefore, it is of vital importance to those hotels (and Croatian hospitality industry in general) to attract new consumers and to expand the season by offering and promoting an attractive, differentiate and innovative range of higher value-added products and experiences.

Table II Overall technical efficiency (OTE) scores of Croatian hotels

\begin{tabular}{|l|r|l|l|l|l|l|r|}
\hline DMU & CCR & DMU & CCR & DMU & CCR & DMU & CCR \\
\hline DMU1 & 100 & DMU19 & 35.26 & DMU37 & 48.44 & DMU55 & 45.81 \\
\hline DMU2 & 54 & DMU20 & 30.09 & DMU38 & 63.55 & DMU56 & 40.47 \\
\hline DMU3 & 59 & DMU21 & 28.07 & DMU39 & 100 & DMU57 & 41.64 \\
\hline DMU4 & 100 & DMU22 & 22.92 & DMU40 & 54.21 & DMU58 & 43.74 \\
\hline DMU5 & 99.48 & DMU23 & 55.25 & DMU41 & 57.81 & DMU59 & 51.16 \\
\hline DMU6 & 57.95 & DMU24 & 39.83 & DMU42 & 42.15 & DMU60 & 27.47 \\
\hline DMU7 & 58.7 & DMU25 & 32.92 & DMU43 & 49.5 & DMU61 & 31.28 \\
\hline DMU8 & 44.72 & DMU26 & 98.72 & DMU44 & 49.36 & DMU62 & 44.2 \\
\hline DMU9 & 67.2 & DMU27 & 52.82 & DMU45 & 60.25 & DMU63 & 48.71 \\
\hline DMU10 & 32 & DMU28 & 67.8 & DMU46 & 55.55 & DMU64 & 59.71 \\
\hline DMU11 & 77.47 & DMU29 & 53.45 & DMU47 & 39.86 & DMU65 & 51.15 \\
\hline DMU12 & 66.39 & DMU30 & 61.93 & DMU48 & 24.02 & DMU66 & 36.13 \\
\hline DMU13 & 39.77 & DMU31 & 57.78 & DMU49 & 50.38 & DMU67 & 46.23 \\
\hline DMU14 & 49.41 & DMU32 & 47.09 & DMU50 & 55.38 & DMU68 & 26.33 \\
\hline DMU15 & 34.6 & DMU33 & 50.2 & DMU51 & 50.67 & DMU69 & 40.38 \\
\hline DMU16 & 44.74 & DMU34 & 54.5 & DMU52 & 43.18 & & - \\
\hline DMU17 & 47.12 & DMU35 & 40.51 & DMU53 & 31.38 & & - \\
\hline DMU18 & 51.43 & DMU36 & 52.47 & DMU54 & 65.18 & & - \\
\hline Average & & & & & & & 51.32 \\
\hline $\begin{array}{l}\text { No of } \\
\text { eff. }\end{array}$ & & & & & & & - \\
\hline $\begin{array}{l}\text { \% of } \\
\text { eff. }\end{array}$ & & & & & & \\
\hline Souce: $A 4 h 015$ &
\end{tabular}

Source: Authors' calculation

After the efficiency scores for all analysed hotels were estimated in the first stage of the analysis obtained scores were used as regressand variable in the second stage of the research in which hotel's ownership, age, location, size and star rating were applied as independent variables.

Table III and Table IV brings descriptive statics and results of the correlation analysis among regressors used in truncated regression. Table III confirms previously determined average hotels' efficiency score of $51.32 \%$, with the lowest level of efficiency $(22.92 \%)$ recorded by DMU22 and the highest level of efficiency $(100 \%)$ documented by DMU1, DMU4 and DMU39. As ownership and location are dummy variables, their value amounted 1 or 0 depending on whether the hotel belong or not belong to previously defined group. The oldest hotel in the sample is 48 years old, whereas the youngest one is established 7 years ago (in 2014). Size of hotels span from
16.56 to 21.45 , whereas the majority of hotels $(66.6 \%)$ have 4 stars rating.

Table III Descriptive statistics

\begin{tabular}{|c|c|c|c|c|}
\hline Variable & Mean & Std. Dev. & Min & Max \\
\hline Efficiency (OTE) & 51.31696 & 17.7256 & 22.92 & 100 \\
\hline Ownership (O) & 0.376811 & 0.488137 & 0 & 1 \\
\hline Age (A) & 24.05797 & 7.646383 & 7 & 48 \\
\hline Location (L) & 0.797101 & 0.405104 & 0 & 1 \\
\hline Size (S) & 18.27876 & 1.05073 & 16.5687 & 21.4528 \\
\hline $\begin{array}{c}\text { Number of stars } \\
(\mathrm{Q})\end{array}$ & 3.855072 & 0.60087 & 2 & 5 \\
\hline
\end{tabular}

Source: Authors' calculation

Table IV Correlation analysis among regressors used in truncated regression

\begin{tabular}{|c|c|c|c|c|c|}
\hline Variable & $\begin{array}{c}\text { Ownership } \\
(\mathrm{O})\end{array}$ & $\begin{array}{c}\text { Age } \\
(\mathrm{A})\end{array}$ & $\begin{array}{c}\text { Location } \\
(\mathrm{L})\end{array}$ & $\begin{array}{c}\text { Size } \\
(\mathrm{S})\end{array}$ & $\begin{array}{r}\text { Number } \\
\text { of stars (Q) }\end{array}$ \\
\hline $\begin{array}{c}\text { Ownership } \\
(\mathrm{O})\end{array}$ & 1.000 & & & & \\
\hline Age (A) & -0.132 & 1.000 & & & \\
\hline Location (L) & $-0.277^{*}$ & -0.115 & 1.000 & & \\
\hline Size (S) & $-0.523^{* *}$ & $0.288^{*}$ & $0.266^{*}$ & 1.000 & \\
\hline $\begin{array}{c}\text { Number of } \\
\text { stars (Q) }\end{array}$ & $0.239^{*}$ & 0.015 & -0.002 & 0.192 & 1.000 \\
\hline
\end{tabular}

Source: Authors' calculation

As regards correlation analysis presented in Table IV, it can be stated that coefficients of all analysed independent variables are far below 0.7 , suggesting no presence of multicollinearity, therefore we could proceed with the truncated regression for which the results are present in Table V. Although the truncreg output retrieved from Stata does not include neither an $\mathrm{R}^{2}$ nor a pseudo- $\mathrm{R}^{2}$, it is possible to compute its rough estimation, which in this research amounted 0.35 or $35 \%$.

Table V Results of truncated regression (dependent variable OTE)

\begin{tabular}{|c|c|c|}
\hline Variable & Coef & $\mathrm{P}>|\mathrm{z}|$ \\
\hline Ownership (O) & 8.780378 & 0.024 \\
\hline Age (A) & 0.157459 & 0.437 \\
\hline Location (L) & 11.18316 & 0.005 \\
\hline Size (S) & 3.738276 & 0.047 \\
\hline Star rating (Q) & 7.689629 & 0.005 \\
\hline Cons & -64.44512 & 0.040 \\
\hline /sigma & 11.83238 & 0.000 \\
\hline
\end{tabular}

Source: Authors' calculation

Of all analysed variables only age of the hotel did not prove to be statistically significant. Ownership variable shows statistically significant difference between efficiency of independent hotels and those belonging to a chain of hotels, in favour of the former. In other words, independent hotels seem to be more efficient than chain hotels. A possible explanation for that can be found in the fact that independent hotels are 
more flexible in adjustments of their standards and practices/policies in order to meet changing market needs. They are also more flexible in adoption to local condition. Indeed, similar results were recorded by [15] which found that international hotels exhibit low efficiency due to their low ability to adjust to local market condition. Empirical results also partially coincide to those of [28] and [29] which found (in)significant difference between chain hotels and independent ones, depending on the measure of performance used in the research. Hence, hotels must weigh all benefits of belonging to a chain (e.g. obtained better distribution network; reduced cost of advertising, reservation system and management teams through economies of scale that are obtained by sharing these costs with other chain members, etc.) against all costs (e.g. lower level of flexibility; payment of different types of fees; going through expensive and stringent qualification evaluation, etc.) and pursue a policy of its best interest [30].

Location of the hotel also plays significant role in achieving higher level of efficiency. Hotels that are located in the county by the sea perform better than those located away from the coast. This is not surprising knowing that Croatian tourism is highly seasonable as it is based on "sea and sun" tourism concept in which majority of tourism arrivals are realised during the summer months and are concentrated in coastal areas. As $20 \%$ of Croatian GDP is realised through tourists' expenditure (it is worth noting that this represents the largest share realised in the European Union), it is important that Croatia supply new tourism services that will alleviate risk of stagnation and help in maximization of tourism impact on other sectors of the economy [31]. This is in accordance with the Croatian tourism development strategy that emphasizes the prominence of diversified product development in order to cut down seasonality. Precisely, aside from "sun and sea" concept, additional tourism product development should be made in health tourism, cultural tourism, nautical tourism, golf tourism, MICE tourism, wine and gastro tourism, adventure and sport tourism, as well as in rural and mountain tourism. These products developments will not only expand the season, but also contribute to the improvement of the efficiency of hotels that are not necessary located on the coast. The importance of hotel's location on its performance is also confirmed in papers of [32] and [33]. However, some authors did not manage to find significant influence of hotel's location on its performance, e.g. [34]. Still, in later research hotels were distinguished depending on whether they were located in the capital city or in remote areas, what is different from our classification in which hotels were separated depending on whether they were located near the coast or not.

Size of the hotel has positive and statistically significant impact on its efficiency. The larger is the hotel, the higher level of efficiency is achieved. It is well known that due to their size, the larger hotels are able to obtain economies of scale and supply their services at lower costs. These findings are opposite to those of [13], which recorded negative relationship between the efficiency and hotel size. Still, they are in line with the results of [35] and [36] which confirmed positive influence of hotel's size on its performance, where former stated that larger hotels achieve higher gross operating profit and occupancy rate than smaller ones primarily due to economies of scale in transactions and operational advantages. Large hotels may also enjoy high occupancy and sales revenue as they can provide a range of leisure and services activities (i.e. food and beverages, accommodation, animation and entertainment for guests' children, spa, gym, laundry, swimming pool, conference facilities, etc.) which in turn enables them to achieve higher efficiency. These arguments correspond to [37] which found not only the evidence that product-specific scale economies exists in food and beverage, accommodation, and in other services in hotels, but also discovered the presence of economies of scope in providing accommodation and food and beverage services jointly. The presence of economies of scale and scope hence may initiate some incentives for M\&A activities among small and medium sized hotels, and thus increase their efficiency.

Finally, star rating significantly and positively influence hotel's efficiency. According to the obtained results, the more stars a hotel has the more efficient it is. As the quality of hotel is strongly associated with the number of its stars (which provide information on basic facilities that travellers can expect in particular hotel) it is clear that (given the results) the higher quality/luxury hotels are more efficient. A deeper insight into the results shows that the efficiency achieved by 2star, 3-star, 4-star and 5-star hotels amounted 24\%, 42.7\%, $50.9 \%$ and $75.8 \%$ respectively, thus strongly indicating the importance of high-star hotels and their predominance in terms of efficiency. This finding stress the importance and necessity of upgrading the quality of existing hotels and, if needed, concentrating on building mainly high-star hotels. Moreover, as most hotels from our sample provide a relative oversupply of rooms/beds, a part of a hotels' accommodation capacity can be renovated/rearranged in sections offering leisure, entertainment, health service, etc. Influence of hotels star rating on its efficiency and occupancy is confirmed by [8] and [34] respectively, whereas [13] demonstrated no statistically significant association between efficiency and hotel quality.

\section{CONCLUSION}

The aim of this paper was twofold. First, to examine relative efficiency score for 69 large and medium-size hotels that were operating in the Croatia in 2019, and second, to identify relevant sources of hotels (in)efficiency. Using the DEA methodology in the first step of the analysis, in which four inputs (number of rooms, number of beds, costs of raw materials and supplies, and number of employees) and one output (operating revenue) were chosen as variables that on the most convenient way describe functioning of hotel industry, it was possible to evaluate efficiency of each hotel in term of a single efficiency score. According to the obtain scores, hotels were identified as efficient (with efficiency score equal to $100 \%$ ) or inefficient (with efficiency score less than 100\%). As 
efficient hotels form efficiency frontier and represent reference set for all inefficient hotels, their operating practice can serve as a pattern that inefficient hotels should follow. In other words, while using efficient hotels as benchmarks, inefficient hotels may directly improve their business performance by readjusting their input/output combination and by finding and implementing adequate strategies that will help them to create and if possible sustain competitive advantages. There is no universal formula for success. As each hotel has its own specific characteristics, each hotel should implement its own particular mix of different strategy in order to enhance its performance. Still, some general recommendation can be pointed out. Since profitability and efficiency are closely related, they could be raised either through revenue/output maximization (increasing the price of goods/services or increasing the occupancy) and/or through cost/input minimization (decreasing the costs of each particular goods/services). Decision to implement price increase policy is directly related to the price elasticity of demand. Only in case when the demand for product/service is inelastic (below 1), an increase in price will lead to increase in hotel's revenue. Otherwise, if the demand for product/service is elastic (above 1), increase in price will further decrease hotel's revenue. Likewise, by offering and promoting an attractive, differentiate and innovative range of higher value-added products and experiences, it would be possible to attract new consumers, increase the occupancy, penetrate new markets as well as to expand the season. On the other hand, in order to perform successful cost reduction, it is important to decrease only unnecessary expenses, since reduction in costs related to service quality and customer satisfaction can produce negative effects.

The results of the truncated regression in which efficiency scores were used as dependent variable, show that of all analysed independent variables (hotel's ownership, age, location, size and hotel's star rating), only age of the hotel has no significant influence on achieved level of efficiency. Precisely, empirical results reveal that: (1) independent hotels are more efficient than chain hotels; (2) hotels located in the county by the sea perform better than those located away from the coast; (3) larger hotels achieve a higher level of efficiency than their smaller counterparts; (4) hotels that have a higher star rating are more efficient than those with lower star rating. In line with stated, when deciding whether to be independent hotel or a part of chain, top managers must weigh all benefits of belonging to a chain against all costs, and pursue a policy of hotel's best interest. Likewise, aside from "sun and sea" concept, additional tourism product development should be made in health tourism, cultural tourism, nautical tourism, wine and gastro tourism, adventure and sport tourism, etc. Furthermore, as large hotels are characterised by the presence of economies of scale and scope, some incentives for M\&A activities among small and medium sized hotels may arise. Finally, due to the importance of high-star hotels and their predominance in terms of efficiency, it is important to upgrade the quality of existing hotels.

The suggestion for future research might be to evaluate overall, pure and scale efficiency of hotels operating in other
European hospitality industry, especially in those countries characterised by the seasonal seaside tourism. Moreover, a cross-country analysis of factors that determine efficiency can be performed as well as further extend by introducing new variables. In addition, future research may focus on conducting a longitudinal study and carrying out trend analysis of efficiency.

\section{REFERENCES}

[1] S. Proenca, E. Soukiazis, „Tourism as an economic growth factor: a case study for Southern European countries. Tourism Economics",14(4), 2008, pp. 791-806.

[2] United nations world tourism organization, "World Tourism Barometer January 2020", Volume 18, Issue 1, 2020, pp. 1-6

[3] Horwath HTL, Analiza poslovanja hotelijerstva u Hrvatskoj s prijedlozima mjera za unapređenje stanja sektora, 2010, pp. 1-6.

[4] The Institute of Economics Zagreb, "Sektorske analize - Turizam " 2020, pp. 1-49.

[5] Hrvatska turistička zajednica, "Smještajni kapaciteti Hrvatskog turizma s analizom popunjenosti po vrstama smještajnih kapaciteta",2020, pp. 3-26.

[6] R.C. Morey, D.A. Dittman, "Evalatn a hotel GM's performance: A case study in benchmarking", Cornell Hotel and Restaurant Administration Quarterly, 36(5),1995, pp. 30-35.

[7] A. Oukil, A Al-Zidi, "Benchmarking the hotel industry in Oman through a three-stage DEA-based procedure", Journal of Arts and Social Sciences [JASS], 9(2), 2018, pp. 5-23

[8] A. Oukil, N. Channouf, A. Al-Zaidi, "Performance evaluation of the hotel industry in an emerging tourism destination: The case of Oman", Journal of Hospitality and Tourism Management, 29, 2016, pp. 60-68.

[9] L. Li, X. Fei, M. Zhou, "Performance of Taiwan hotel industry using a new Data Envelopment Analysis model", In 2015 11th International Conference on Natural Computation (ICNC), 2015, pp. 1235-1239.

[10] N.Tumer, "Measuring hotel performance using data envelopment analysis",. Anatolia, 21(2), 2010, pp. 271-287.

[11] H. Min, H. Min, S.J. Joo, J. Kim, "A data envelopment analysis for establishing the financial benchmark of Korean hotels", International Journal of Services and Operations Management, 4(2), 2008, pp. 201-217.

[12] Z. Zhou, Y. Huang, M.K. Hsu,"Using data envelopment analysis to evaluate efficiency: An exploratory study of the Chinese hotel industry." Journal of Quality Assurance in Hospitality \& Tourism, 9(3), 2008, pp. 240256

[13] K. Poldrugovac, M. Tekavcic, M., S. Jankovic, "Efficiency in the hotel industry: an empirical examination of the most influential factors", Economic research-Ekonomska istraživanja, 29(1), 2016, pp. 583-597.

[14] R. Oliveira, M.I. Pedro, R.C. Marques, "Cost efficiency of Portuguese hotels in the Algarve: a comparative analysis using mathematical and econometric approaches", Tourism Economics, 20(4),2014, pp. 797-812.

[15] C. Manasakis, A. Apostolakis, G. Datseris, "Using data envelopment analysis to measure hotel efficiency in Crete", International Journal of Contemporary Hospitality Management, 2013, pp. 510-535.

[16] C.A.P. Barros, C.A. Santos, "The measurement of efficiency in Portuguese hotels using data envelopment analysis", Journal of Hospitality \& Tourism Research, 30(3), 2006, pp. 378-400.

[17] A. Higuerey, C. Viñan-Merecí, Z. Malo-Montoya, V.A. MartínezFernández,"Data Envelopment Analysis (DEA) for Measuring the efficiency of the hotel industry in Ecuador." Sustainability, 12(4), 1590, 2020, pp. 1-18

[18] A.G. Assaf , F.W. Agbola, "Modelling the performance of Australian hotels: a DEA double bootstrap approach", Tourism economics, 17(1), 2011, pp. $73-89$

[19] C.P. Barros, P.U. Dieke, "Technical efficiency of African hotels", International Journal of Hospitality Management, 27(3), 2008, pp. 438-447

[20] M.J. Farrell, "The measurement of productive efficiency", Journal of the Royal Statistical Society: Series A (General), 120(3), 1957, pp. 253-281.

[21] A. Charnes, W.W. Cooper, E. Rhodes, "Measuring the efficiency of decision making units", European Journal of Operations Research, Vol. 2 No. 6, 1978, pp. 429-441

[22] R.D. Banker, A. Charnes, W.W. Cooper,"Some models for the estimation oftechnical and scale inefficiencies in data envelopment analysis", Management Science, Vol. 30 No. 9, 1984, pp. 1078-1092. 
[23] W.F. Bowlin, "Measuring Performance: An Introduction to Data Envelopment Analysis (DEA)", The Journal of Cost Analysis, 15:2, 1998, pp. 3-27.

[24] O.N. Arunkumar,T.R. Ramanan, "Operational efficiency and its determinants of Indian food and beverages industries: a DEA approach", International Journal of Services and Operations Management, 27(1), 2018, pp.1-18.

[25] A. Rezitis, M. Kalantzi, "Investigating Technical Efficiency and Its Determinants by Data Envelopment Analysis: An Application in the Greek Food and Beverages Manufacturing Industry, Agribusiness", 32(2), 2016, pp. 254-271.

[26] Croatian Financial Agency (FINA), "info.BIZ 2.0"-database of Financial Agency, 2019, Available at: https://infobiz.fina.hr/Login?ReturnUrl=\%2F

[27] R. Machado de Andrade R, S. Lee, P. Tae-Woo Lee, O. Kyoung Kwon, H. Min Chung, "Port Efficiency Incorporating Service Measurement Variables by the BiO-MCDEA: Brazilian Case Sustainability" 11(16):4340, 2019, pp. 1-18.

[28] E. Menicucci, "The influence of firm characteristics on profitability" ,International Journal of Contemporary Hospitality Management, 2019.

[29] F. Rotondo, N. Fadda, "The influence of being part of a tourist network on hotels' financial performance", International Journal of Hospitality Management., 2018.

[30] J.K. Shang, F.C. Wang, W.T. Hung, "A stochastic DEA study of hotel efficiency", Applied Economics, 42(19), 2010, pp. 2505-2518.

[31] K. Orsini, V. Ostojić, "Croatia's tourism industry: beyond the Sun and Sea" (No. 036), Directorate General Economic and Financial Affairs (DG ECFIN), European Commission, 2018.

[32] R. Lado-Sestayo, M. Vivel-Búa, L. Otero-González, "Connection between hotel location and profitability drivers: an analysis of locationspecific effects", Current Issues in Tourism, 2018, pp. 1-18.

[33] R. Lado-Sestayo, M. Vivel-Búa, "Hotel profitability: a multilayer neural network approach", Journal of Hospitality and Tourism Technology, 11(1), 2020, pp. 35-48.

[34] K. Zaki, O. Qoura, "Profitability in Egyptian hotels: business model and sustainability impact." Research in Hospitality Management, 9(2), 2019,pp. 89-98.

[35] E. Menicucci, G. Paolucci, N. Paoloni, "Does gender matter for hotel performance? Evidence from the Italian hospitality industry", International Journal of Tourism, 2019.

[36] R.B..Babajee, B. Seetanah, R. Nunkoo, "The determinants of hotel financial performance: an intellectual capital perspective", Journal of Hospitality Marketing \& Management, 2020, pp. 1-19.

[37] C.C. Weng, K.L. Wang, "Scale and scope economies of international tourist hotels in Taiwan",Tourism Management, 25(6), 2004, pp. 761-769.

\section{Creative Commons Attribution License 4.0 (Attribution 4.0 International, CC BY 4.0)}

This article is published under the terms of the Creative Commons Attribution License 4.0

https://creativecommons.org/licenses/by/4.0/deed.en_US 